\title{
FROM THE FOUNDING EDITOR
}

\section{Lesbian, Gay, Bisexual, and Transgender People, and the Nursing Imperative}

\author{
Marie Manthey, MNA, FRCN, FAAN
}

\begin{abstract}
This essay speaks to the legacy value of nurses' caring for all people, no matter how they feel about the person's values or lifestyle, including the current issues around gender identity and sexual orientation. This legacy is deeply imbedded in the moral ethics of nursing and supports the proposition that if there isn't caring, it isn't nursing.
\end{abstract}

Keywords: morality; ethics; caring; LGBT persons; definition of nursing; nobility of nursing

role want to share with you my thoughts about nursing's role in caring for people who are lesbian, gay, bisexual, transgender, or anyone who is anywhere at all on the spectrum of gender identification, gender expression, or sexual orientation. My mentor Virginia Henderson's definition is a solid place for me to ground my thinking. She said:

The unique function of the nurse is to assist the individual, sick or well, in the performance of those activities contributing to health or its recovery (or to a peaceful death) that [they] would perform unaided if [they] had the necessary strength, will or knowledge. And to do this in such a way as to help [them] gain independence as rapidly as possible. (Henderson, 1991, p. 21)

A founding value of nursing is a commitment to care compassionately for all humans, regardless of any characteristic, ethnicity, behavior, quality, or value that nurses may find unsavory outside of work. When a patient's gender identification, gender expression, and/or sexual orientation falls outside of the realms of "straight" and "cis gender," the nurse's commitment to caring is no different. No nurse gets a pass because they find someone's gender presentation confusing, or because they're being asked to call someone by a name or pronoun that makes the nurse uncomfortable. Just as we now commonly recognize a patient's family as the group of loved ones the patient tells us are family, without regard to whether they are blood relatives or legal guardians or spouses, we now must recognize all patients' gender identities as the identities our patients claim. No matter what the patient's physiological realities are now or were at birth, socially and relationally, the patient has the right to tell us about their gender, and socially and relationally, we must accept what the patient tells us.

The ancient foundational moral character of nursing is caring. This ancient reality is magnificently brought to the present in a book by Mark Lazenby, entitled Caring Matters Most: The Ethical Significance of Nursing (2017). Lazenby characterizes nursing as "a vocation with a profound morality built into its very nature" (p. 6). He states that because people are vulnerable, we are required to care about and for them in ways that protect them, improve their lives, and convey that they matter. This fundamental commitment to caring "grounds the actions of an individual nurse in the moral character of the profession" (p. 10). He goes on to say, ". . . [W]ithout caring about people in their vulnerability and caring for them with the aim of bringing about for them in the here and now a better world-without this deep commitment to caring as the greatest thing-nursing is not nursing" (p. 10).

The moral ethic of nursing is caring. If your personal morality doesn't allow you to call someone by their preferred name or pronoun, I would lovingly ask you to reconsider your vocation. 
Rapid changes in a society will continually present challenges to the status quo, especially if the new culture is challenging age-old values and principles that are familiar and comfortable to the majority of people. Currently, a sea change is challenging society's notions about gender identification, gender expression, and sexual orientation. A small but growing segment of people are redefining their understanding of themselves, and they are also-quite rightlyunwilling to pretend to be who and what they are not.

If you do not already know and love someone who identifies as being something other than male or female, or someone whose gender identification or expression does not match the gender they were assigned based on the anatomy they were born with, this may be a particularly hard subject for you. But if you had a child who was neither straight nor cis gender, you would likely, given enough time, have reconciled yourself to the reality of your loved one's life. And, as a nurse, if you haven't already made this reconciliation, it's time for you to do it. No one is going to tell you this work is easy. To be in relationship with anyone you perceive as being different from you-particularly if they are a member of an oftenpersecuted group-is to fail at times in that relationship. You will make mistakes. Continue to do your best, ask the person's forgiveness, and remember that your job as a nurse is, first and foremost, to care.

I remember being asked quite early in my career to describe my highest hope regarding health care. My highest hope has always been to humanize health care by humanizing the way people are cared for. Humane care of individuals who identify as lesbian, gay, bisexual, transgender, questioning, queer, intersex, gender-nonbinary, pansexual, Two-Spirit, androgynous, or asexual is perhaps the highest form of personal, loving care a nurse can imagine. Humane care means care that recognizes and supports all aspects of a person's humanity.

Florence Nightingale said, "It is a noble calling, the calling of Nurses but it depends on you nurses to make it noble" (as cited in Ulrich, 1992, p. 54). I believe nursing is noble when a nurse enters into a caring relationship nonjudgmentally, accepting the humanity of each patient and recognizing the privilege we

No matter what the patient's
physiological realities are now or
were at birth, socially and
relationally, the patient has the
right to tell us about their gender,
and socially and relationally, we
must accept what the
patient tells us.

have to interact with vulnerable humans in a way that reduces their vulnerability and increases their comfort. Humane care is the moral and ethical foundation of nursing.

\section{REFERENCES}

Henderson, V. (1991). The nature of nursing: Reflections after 25 years. Washington, DC: National League for Nursing.

Lazenby, M. (2017). Caring matters most: The ethical significance of nursing. New York, NY: Oxford University Press.

Ulrich, B.T. (1992). Leadership and management according to Florence Nightingale. Appleton \& Lange.

Disclosure. The authors have no relevant financial interest or affiliations with any commercial interests related to the subjects discussed within this article.

Funding. The author received no specific grant or financial support for the research, authorship, and/or publication of this article.

Correspondence regarding this article should be directed to Marie Manthey at mmanthey@chcm.com

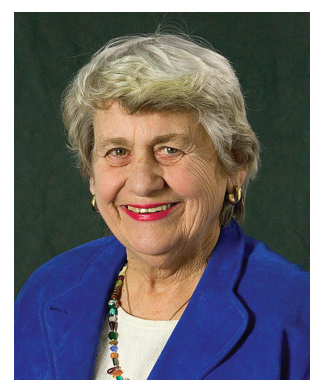

Marie Manthey, MNA, FRCN, FAAN (she/her/hers), is President Emeritus of Creative Health Care Management and Founding Editor of Creative Nursing. 